Tropical Journal of Pharmaceutical Research September 2019; 18 (9): 1913-1917

ISSN: $1596-5996$ (print); 1596-9827 (electronic)

(C) Pharmacotherapy Group, Faculty of Pharmacy, University of Benin, Benin City, 300001 Nigeria.

Available online at http://www.tjpr.org

Original Research Article

http://dx.doi.org/10.4314/tjpr.v18i9.19

\title{
Effect of Zaoxiu ointment on wound-healing in experimental second degree burns rats
}

\author{
Xiong Wang ${ }^{1}$, Li Ma ${ }^{1}$, Meng-ling Huang ${ }^{2}$, Yong-gang Chen ${ }^{1}$ and Jin-hu Wu ${ }^{1 *}$ \\ ${ }^{1}$ Department of Pharmacy, Tongren Hospital of Wuhan University (The Third Hospital of Wuhan), Wuhan 430060, ${ }^{2}$ College of \\ Pharmacy, Hubei University of Traditional Chinese Medicine, Wuhan 430065, Hubei Province, China
}

*For correspondence: Email: wujinhu133@126.com; Tel: +86 027-68894852

Sent for review: 20 December 2018

Revised accepted: 25 August 2019

\begin{abstract}
Purpose: To evaluate the healing efficacy of a Traditional Chinese Medicine (TCM) preparation Zaoxiu Burn Ointment (ZBO) on experimental burns in rats.

Methods: The rats were randomly divided into four groups of eight rats each: control group, silver sulfadiazine (SSD)-treated group, moist exposed burn ointment (MEBO)-treated group and ZBO-treated group. ZBO, SSD and MEBO were applied topically twice daily for 7 days. SSD and MEBO were used as reference control. The observation of wound area contraction and histological analysis of wound tissues were performed. The effect of ZBO on MMPs, VEGF and Type-IIl collagen proteins of wound tissue in rats were determined by Western blot.

Results: After 10 days of topical treatment with ZBO, ZBO-treated group showed faster reduction in wound area in comparison with control groups $(p<0.01)$. MMP-2, MMP-9, VEGF and type-III collagen expression of the wound tissue increased significantly $(p<0.05)$ in comparison with the control burn wounds in rats. The ZBO had no cytotoxic effect on BHK-21 cell line. Histological results showed an overall early recovery and regeneration in ZBO-treated group when compared with control group.

Conclusion: ZBO possesses significant wound-healing activity in full-thickness burn wounds in rats, and can potentially be developed for the treatment of burns patient in future.
\end{abstract}

Keywords: Zaoxiu burn ointment, Second-degree burns, wound-healing

\begin{abstract}
This is an Open Access article that uses a fund-ing model which does not charge readers or their institutions for access and distributed under the terms of the Creative Commons Attribution License (http://creativecommons.org/licenses/by/4.0) and the Budapest Open Access Initiative (http://www.budapestopenaccessinitiative.org/read), which permit unrestricted use, distribution, and reproduction in any medium, provided the original work is properly credited.

Tropical Journal of Pharmaceutical Research is indexed by Science Citation Index (SciSearch), Scopus, International Pharmaceutical Abstract, Chemical Abstracts, Embase, Index Copernicus, EBSCO, African Index Medicus, JournalSeek, Journal Citation Reports/Science Edition, Directory of Open Access Journals (DOAJ), African Journal Online, Bioline International, Open-J-Gate and Pharmacy Abstracts
\end{abstract}

\section{INTRODUCTION}

Burn injuries caused by heat, light, electricity, radiation and chemicals, amongst the most common and devastating forms of trauma, particularly partial- and full-thickness burns [1]. According to the study report, about 5000 10,000 in one million people suffered from burn in China every year [2]. Depending on the severity, burn injuries are classified into three degrees, whereby the second degree is divided into shade and deep degrees [3]. Burn-wound could result in the increase of free radicalmediated damage and reactive oxygen species. It can delay granulation tissue formation, reduce angiogenesis and decrease collagen reorganization. Furthermore, due to its significantly prolonged period of rehabilitation, the healing of burn injuries is more difficult than 
that of ordinary wounds and is also associated with higher economic costs [4].

Current ways to treat burn injuries include antibiotics, antiphlogistics, and silver salt, which possess major drawbacks and unwanted side effects [5]. Nowadays, alternative and complementary medicines, such as Traditional Chinese Medicine and aromatherapy, are being used, because they are moderately beneficial to effective with little toxicity and are less expensive than synthetic drugs. Many plants and plantderived products have been found to possess potent wound-healing or burn-wound-healing activity [6].

Zaoxiu Burn Ointment (ZBO), which is composed of Rhizoma Paridis 5g, Notoginseng radix et Rhizoma 6g, Lithospermum erythrorhizon Sieb. et Zucc.4g, Polygonum bistorta L. 4g, Coptis chinensis Franch. $5 g$, Acacia catechu (L.f.) Willci 6g., Punica granatum L. 3g, Angelica dahurica (Fisch. ex Hoffm.) Benth. et Hook. f. ex Franch. et Sav 5g, Angelica sinensis (Oliv.) Diels $6 g$ and Cynanchum otophyllum. $4 g$, is a Traditional Chinese Medicine preparation for treating burns. It has been used in treatment of inflammation, infection, jaundice, skin burns and hyperlipemia in China $[7,8]$. In the present study, a series of experiments were designed to investigate the effect of ZBO on burn injuries in rats.

\section{EXPERIMENTAL}

\section{Preparation of ZBO}

The medicinal herbs of ZBO were collected from Bozhou City, Anhui Province in China in May 2017. Taxonomic identification of the plants was performed by Prof. Lin Hu of Wuhan University in China. A voucher specimen (NO. ZBO 20170505) was deposited in the College of Pharmacy, Wuhan University, China for future reference. ZBO was provided by the third hospital of Wuhan (Wuhan, China).

\section{MTT assay}

The [3-(4, 5-dimethylthiazol-2-yl)-2,5-diphenyltetrazolium bromide] MTT assay was used to assess cytotoxicity caused by the ZBO extract. BHK-21 cell line was purchased from the Shanghai Institutes for Biological Sciences, Shanghai, China. The cells were maintained at $37{ }^{\circ} \mathrm{C}$ in an incubator with a humidified atmosphere of $5 \% \mathrm{CO}_{2}$ and cultured in Glasgow's; minimum essential medium (GMEM) containing $10 \%$ heat-inactivated fetal calf serum (FCS), streptomycin $(100 \mu \mathrm{g} / \mathrm{mL})$ and neomycin sulfate $(50 \mu \mathrm{g} / \mathrm{mL})$. The BHK-21 cells were seeded on a 24-well plate at $1 \times 10^{5}$ cells $/ \mathrm{mL}$. Sixteen hours after plating, the cells were treated with various concentrations of the ZBO extract $(20,40,80,160,320 \mu \mathrm{g} / \mathrm{mL})$ for $24 \mathrm{~h}$. MTT stock solution ( $80 \mu \mathrm{L} ; 4 \mathrm{mg} / \mathrm{mL}$ ) was then added and incubated for $4 \mathrm{~h}$. The formazan crystals generated in each well were dissolved in $1 \mathrm{~mL}$ of acidified isopropanol and read spectrophotometrically at $550 \mathrm{~nm}$.

\section{Experimental animals and burns wound model preparation}

Wistar rats, weighing $200-220$ g, were obtained from Hubei Center for Disease Control and Prevention, Wuhan, Hubei. The animals had free access to food and water, and were allowed to acclimatize for at least one week before use. All animal experiments were approved by the Animal Care and Use Committee of The Third Hospital of Wuhan (approval ref no. 20141005) and were carried in compliance with the Animal Welfare Act and the $\mathrm{NIH}$ guidelines $(\mathrm{NIH}$ publication no. 80-23, revised 1996) [9].

After the back hair of the rats was removed, 20 $\%$ ethyl carbamate solution was injected into their abdominal cavities for anesthetic effects. The top of electrical scald instrument (manufactured by Changhai Hospital of Second Military Medical University) was pressed onto the back skin with a certain force for $15 \mathrm{~s}$ at the temperature of $75{ }^{\circ} \mathrm{C}$. A standard deep-second degree burn wound with $200 \mathrm{~mm}^{2}$ area was induced through the pathological examination of wounded skins.

\section{Experimental design}

All rats were randomly divided into four groups of eight rats in each: control group, SSD-treated group, MEBO-treated group and ZBO-treated group. All rats were induced into a deep second degree burn model. ZBO was applied topically and twice daily for 7 days in rats. Silver sulfadiazine (SSD) cream USP, $1.0 \% \mathrm{w} / \mathrm{w}$ and moist exposed burn ointment (MEBO) were used for treating reference controls. Control group received the vehicle water alone in an identical manner.

\section{Assessment of wound area contraction}

The wound surface area of rats was traced on a transparent paper and measured planimetrically [10].

\section{Histological examination}

The wound tissues of rats were fixed in $10 \%$ 
formalin. After fixation, samples were embedded in paraffin, cut into $3 \mathrm{~mm}$ frozen sections with a cryostat microtome, and then stained with hematoxylin eosin reagent. Collagen fiber, inflammatory cell, blood vessel, fibroblast and granulation tissue of burn skin of rats were observed under the microscope.

\section{Western blot analysis}

Wound tissues were cut into small pieces and collected in Tris buffer (50 mM, pH 6.8) containing protease inhibitors, phenyl methyl sulfonyl fluoride (PMSF) and aprotonin (Sigma, St Louis, MO, USA) at 10 and $2 \mu \mathrm{g} / \mathrm{mL}$. Tissues were homogenized in Polytron homogenizer (PT 3100, Kinematica AG, Littau-Lucerne, Switzerland) with four strokes of $15 \mathrm{~s}$ each in ice bath. Analysis of total protein in the tissue samples was done by PAGE in $4 \%(\mathrm{v} / \mathrm{v})$ stacking and $10 \%$ (v/v) separation polyacrylamide gels in the presence of SDS, followed by staining with CBR-250.

The homogenized tissue samples mixed in a sample buffer containing $1 \%$ SDS, $2 \% 2-$ mercaptoethanol and $10 \%$ glycerol were reduced in a boiling water bath, whereas the gel and running buffer contained 0.1 and $0.2 \%$ SDS. The molecular weight of protein was detected using standard protein markers (broad range 200-6.9 kDa, Bio-Rad, Hercules, CA, USA).

After electrophoretic separation of tissue proteins by SDS-PAGE, the proteins were electrotransferred on to a polyvinylidene difluoride (PVDF) membrane. The membrane was blocked for $1 \mathrm{~h}$ in Tris-buffered saline with $0.1 \%$ Tween20 (TBST, pH 7.5) containing $5 \%$ milk protein. After incubation with rabbit polyclonal primary antibody (MMP-2, MMP-9 and VEGF, Santa Cruz Biotechnology, CA, USA) and mouse monoclonal primary antibody (Collagen type-III, Sigma) for $2 \mathrm{~h}$, the blots were washed extensively with TBST. Primary antibodies were revealed via incubation with alkaline phosphatase-conjugated secondary antibody, goat-anti-rabbit and goat-anti-mouse (Santa Cruz Biotechnology), respectively for $1 \mathrm{~h}$. The blots then were developed with 5-bromo-4-chloro-3indolyl phosphate/nitro blue tetrazolium (BCIP/NBT) liquid substrate system (Sigma) [11].

\section{Statistical analysis}

Data are expressed as mean \pm SE, and statistical significance between experimental and control values was analyzed by one-way ANOVA followed by Dunnett's test using Graph Pad Prism 2.01 (Graph Pad Software Inc., La Jolla, CA, USA). A P-value $<0.05$ was considered statistically significant.

\section{RESULTS}

\section{Effect of ZBO on wound area contraction}

ZBO was most effective drug for wound-healing activity. Table 1 depicts the effect of topical application of ZBO on wound area reduction at different time intervals. The animals treated with ZBO showed significant reduction in wound area on day 5 (112.00 versus $126.34 \mathrm{~mm}^{2}$ in the untreated group) and day 10 (42.16 versus 91.57 $\mathrm{mm}^{2}$ in the untreated group) post wounding (Table 1).

\section{Histological features}

On the day 10, the ZBO group showed more advanced re-epithelialization and layering with continuous basement membrane in addition to a better organization of the collagen bundles. The ZBO, SSD and MEBO treated animals showed reduced congestion, edema and polymorphonuclear leukocytes infiltration. The control group showed many distinct space between old and new regenerating layers of epithelium. Histological studies showed an overall early recovery and regeneration in the ZBO treated group when compared with control group (Figure 1).

\section{Effect of ZBO on MMPs, VEGF and type-III collagen proteins of wound tissue}

Western blot analysis showed that after 10 days of topical treatment with ZBO, MMP-2 and MMP9 expression of the wound tissue increased in comparison with the control burn wounds. Upregulated expression of VEGF and type-III collagen in ZBO treated wounds were observed significantly compared with untreated control burn wounds (Figure 2).

Table 1: Effect of topical application of ZBO on wound area contraction $\left(\mathrm{mm}^{2}\right)$

\begin{tabular}{|c|c|c|c|c|}
\hline Day & Control group & SSD group & MEBO group & ZBO group \\
\hline Day 0 & $202.15 \pm 0.38$ & $187.35 \pm 0.74$ & $189.41 \pm 1.12$ & $186.35 \pm 1.25$ \\
\hline Day 5 & $131.27 \pm 3.86(22)$ & $115.64 \pm 4.86(22)$ & $117.16 \pm 3.47(19)$ & $124.31 \pm 3.14^{\pi}(29)$ \\
\hline Day 10 & $96.37 \pm 2.26(43)$ & $72.13 \pm 3.57(54)$ & $68.74 \pm 3.46^{\prime}(57)$ & $45.62 \pm 3.28^{\circ \prime}(69)$ \\
\hline
\end{tabular}




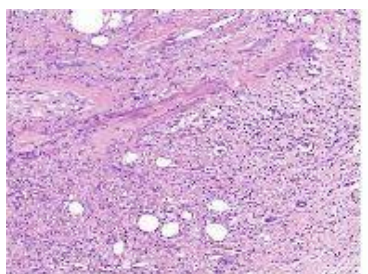

A

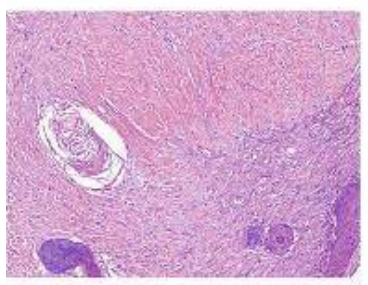

C

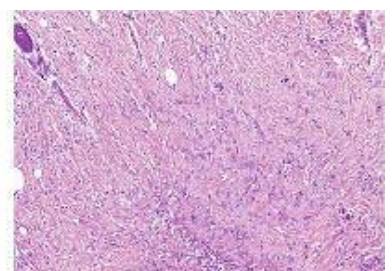

B

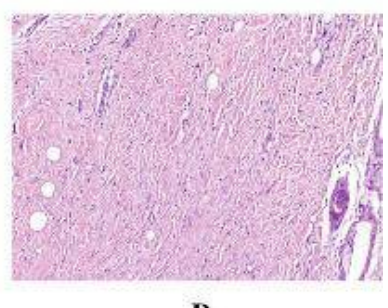

D
Figure 1: Photographs of pathological sections of burn skin. A: Control group; B. SSD group; C. MEBO group; D: ZBO group at day 10 (Original magnification, 200x)
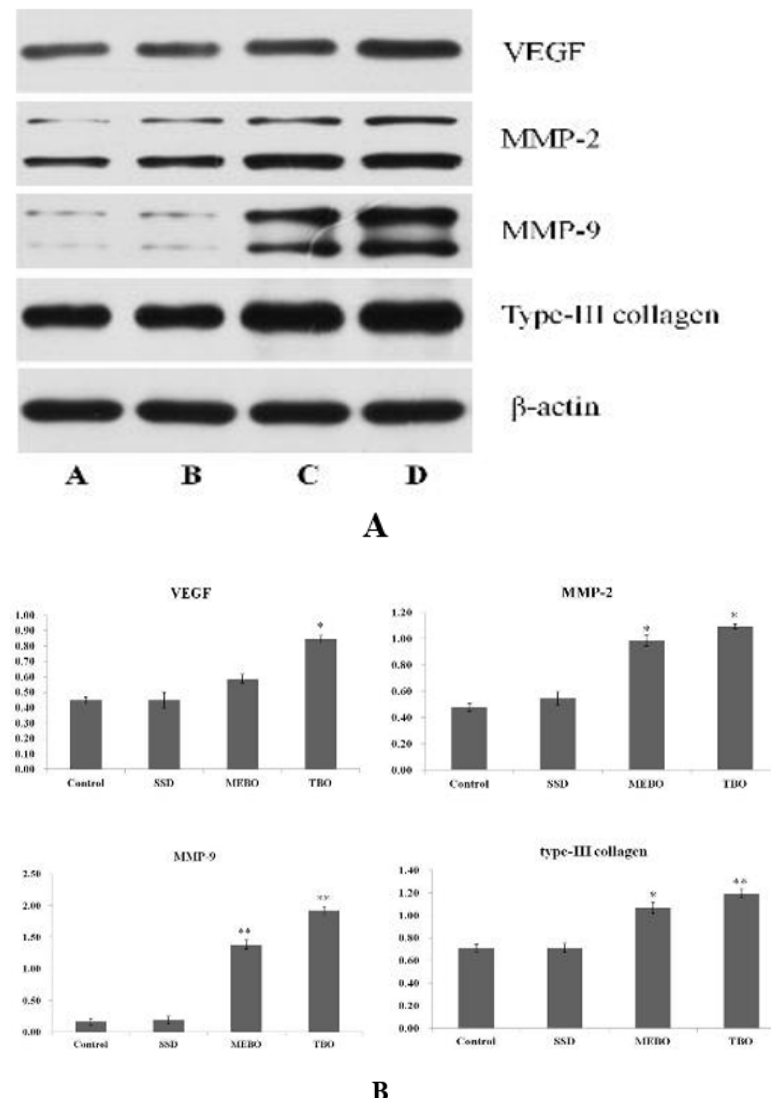

Figure 2: Western blot $(A)$ and quantitative result $(B)$ of MMP-2, MMP-9, VEGF and Type-III collagen in wound tissue. A: Control group; B. SSD group; C. MEBO group; D: ZBO group. $P<0.05, \quad p<0.01$ compared with burn control group

\section{DISCUSSION}

Thermal burn injury is still a major cause of death and disability in the world and its healing process is a challenge in modern medicine. Burn in human body may be treated by different methods depending on the extent and severity of the burn. SSD could kill a wide variety of bacteria, so it is commonly used to prevent and treat infections of the second and third degree burns. Recent studies revealed that SSD ointment had positive effects on proliferation of fibroblasts which are the main source of collagen and fibronectin [12]. However, current reports suggest that silverbased products should be avoided due to their side effects and researchers are making efforts to seek better topical antimicrobial products.

The results of the present study indicate that the ZBO promotes wound healing in experimental burn wounds. The increased wound contraction in ZBO treated rats might be due to an enhanced activity of fibroblasts in regenerated wound tissue. Myofibroblasts are believed to play a key role in wound contraction by exerting tension on the surrounding extracellular matrix (ECM) and secreting ECM proteins such as collagen to stabilize the contraction. Collagen is a major protein of ECM and component that ultimately contributes to wound strength [13]. Enhanced expression of collagen type-III in SBT treated burn wounds were observed when compared with untreated control group. Collagen type-III is a predominant form of collagen in the early stages of wound healing that helps in providing strength to the provisional ECM [13].

MMPs are key players in every phase of the healing process, such as eliminating damaged protein, destroying the provisional ECM, facilitating migration to the center of the wound, remodelling the granulation tissue, controlling angiogenesis and also regulating the activity of some growth factors [14]. Increased expression of MMP-2 and -9 in ZBO treated experimental rats suggested that ZBO played an important role in remodeling of the ECM.

\section{CONCLUSION}

The results suggest that ZBO possesses a significant wound-healing activity in full-thickness burn wounds in rats, and therefore, and therefore, would potentially be used for the treatment of burns patient in future.

\section{DECLARATIONS}

\section{Acknowledgement}

This study was supported by the Key Technology Project of Wuhan Municipal Science and 
Technology Bureau of China (no.
2015060202010117).
Conflict of interest
No conflict of interest is associated with this
study.

\section{Contribution of authors}

We declare that this work was done by the authors named in this article and all liabilities pertaining to claims relating to the content of this article will be borne by the authors. Jin-hu Wu designed all the experiment and revised the paper. Xiong Wang and Meng-ling Huang performed the experiment, Yong-gang Chen and Li Ma wrote the paper.

\section{Open Access}

This is an Open Access article that uses a funding model which does not charge readers or their institutions for access and distributed under the terms of the Creative Commons Attribution License (http://creativecommons.org/licenses/by/ 4.0) and the Budapest Open Access Initiative (http://www.budapestopenaccessinitiative.org/rea d), which permit unrestricted use, distribution, and reproduction in any medium, provided the original work is properly credited.

\section{REFERENCES}

1. Nacer KA, Mahlous M, Tahtat D. Evaluation of healing activity of PVA/chitosan hydrogels on deep second degree burn: pharmacological and toxicological tests. Burns 2013; 39: 98-104.

2. Kopp J, Wang GY, Horch RE. Ancient traditional Chinese medicine in burn treatment: a historical review. Burns 2003; 29: 473-478.
3. Edelman LS. Social and economic factors associated with the risk of burn injury. Burns 2007; 33: 958-965.

4. Shanmugasundaram N, Uma TS, Lakshmi TSR, Babu M. Efficiency of controlled topical delivery of silver sulfadiazine in infected burn wounds. J Biomed Mater Res A 2009; 89: 472-482.

5. Peng $W$, Qin $R, L i X$. Botany, phytochemistry, pharmacology, and potential application of Paris polyphylla: A review. J Ethnopharmacol 2013; 148: 729 745.

6. Dorsett-Martin, WA. Rat models of skin wound healing: $A$ review. Wound Repair Regen 2004; 12: 591-599.

7. Hsu CY, Chan YP, Chang J. Antioxidant activity of extract from Zaoxiu Burn Ointment. Biol Res 2008; 43: 15-23.

8. Hsu CY, Chan YP, Chang J. Topical anti-inflammatory activity of Zaoxiu Burn Ointment in the TPA model of mouse ear inflammation. J Inflamm 2009; 6: 11-14.

9. European Commission. Directive 2010/63/EU on the Protection of animals used for scientific purposes [assessed 2013 Jan 16]. Available from: http://ec.europa.eu/environment/chemicals/lab_animals/l egislation_en..htm.

10. Gupta A, Upadhyay NK, Sawhney RC, Kumar R. A polyherbal formulation accelerates normal and impaired diabetic wound healing. Wound Repair Regen 2008; 16 : 784-790.

11. Upadhyay NK, Kumar R, Mandotra SK. Safety and healing efficacy of Sea buckthorn (Hippophae rhamnoides L.) seed oil on burn wounds in rats. Food Chem Toxicol 2009; 47: 1146-1153.

12. Coelho JM, Antoniolli AB, Nunese SD. Effects of silver sulfadiazine, ipêroxo (Tabebuia avellanedae) extract and barbatimão (Stryphnodendron adstringens) extract on cutaneous wound healing in rats. Rev Col Bras Cir 2010; 37: 45-51.

13. Singer AJ, Clark RAF. Cutaneous wound healing. N Engl J Med 1999; 341: 738-746.

14. Inkinen $K$, Turakainen $H$, Wolff $H$, Ravanti L, Ahonen J. Expression and activity of matrix metalloproteinase-2 and -9 in experimental granulation tissue. APMIS 2000; 108: 318-328. 